\title{
Interventional sialendoscopy for radioiodine-induced sialadenitis: quo vadis?
}

\author{
La scialoendoscopia interventistica per le scialoadeniti radioiodio-indotte: \\ quo vadis?
}

\begin{abstract}
P. CANZI ${ }^{1}$, S. CACCIOLA ${ }^{1}$, P. CAPACCIO ${ }^{23}$, F. PAGELLA ${ }^{1}$, A. OCCHINI', L. PIGNATARO ${ }^{24}$, M. BENAZZO
${ }^{1}$ Department of Otorhinolaryngology, University of Pavia, IRCCS Policlinico "San Matteo" Foundation, Pavia, Italy; 2 'Department of Otolaryngology and Head and Neck Surgery, Fondazione IRCCS Ca' Granda Ospedale Maggiore Policlinico, Milan, Italy; ${ }^{3}$ Department of Biomedical, Surgical and Dental Sciences; ${ }^{4}$ Department of Clinical Sciences and Community Health, Università degli Studi di Milano, Milan, Italy
\end{abstract}

\section{SUMMARY}

Salivary gland toxicity is a common adverse effect of radioactive iodine $\left({ }^{131} \mathrm{I}\right)$ for the treatment of thyroid cancers with a prevalence ranging from $2 \%$ to $67 \%$ of the ${ }^{131} \mathrm{I}$ exposed population. Recently, sialendoscopy has been introduced as an attractive diagnostic and therapeutic tool for management of patients with radioiodine-induced sialadenitis that is unresponsive to standard medical treatments. The objective of the current review was to assess the impact of this procedure on outcomes in patients suffering from radioiodine sialadenitis. Overall, eight studies were included and 122 patients underwent 264 sialendoscopic procedures. Duct stenosis and mucous plugs were observed in $85.7 \%$ of endoscopic findings, supporting the role of ductal obstruction in the pathophysiology of radioiodine sialadenitis. In total, $89.3 \%$ of patients experienced complete or partial resolution of sialadenitis recurrences without any major adverse events, and parotidectomy was advocated in only 1 case. However, outcomes mainly concerned subjective reports and only two clinical experiences evaluated objective measurement with dissimilar results. Limited to few studies, xerostomia and obstructive symptoms responded differently after sialendoscopy. The optimal timing of salivary gland videoendoscopy needs to be further analysed in order to define the best management of radioiodine-induced obstructive sialadenitis.

KEY WORDS: Sialadenitis $\bullet$ Radioiodine $\bullet$ Sialendoscopy $\bullet$ Salivary glands $\bullet$ Endoscopy

\section{RIASSUNTO}

La tossicità delle ghiandole salivari rappresenta un noto effetto indesiderato dello iodio radioattivo ( ${ }^{131}$ I) utilizzato per il trattamento di neoplasie tiroidee, con una prevalenza che varia dal $2 \%$ al $67 \%$ della popolazione esposta. Recentemente, la scialoendoscopia è stata introdotta come un interessante strumento diagnostico e terapeutico per la gestione dei pazienti affetti da scialoadenite radioiodio-indotta non responsiva ai trattamenti medici standard. L'obiettivo della presente revisione è stato valutare l'influenza di questa procedura sulla storia clinica di pazienti affetti da scialoadenite conseguente a trattamento con radioiodio. Complessivamente, la revisione ha incluso 8 studi, 122 pazienti e 264 scialoendoscopie. Le stenosi duttali ed i tappi mucosi hanno rappresentato l'85.7\% dei reperti endoscopici, sostenendo il ruolo dell'ostruzione duttale nella fisiopatologia della scialoadenite da radioiodio. Circa l'89.3\% dei pazienti riportarono una risoluzione parziale o completa degli episodi di scialoadenite ricorrente, senza complicanze post-operatorie maggiori. Un solo caso è stato sottoposto a parotidectomia per fallimento del trattamento scialoendoscopico e persistenza dei sintomi. Tuttavia, $i$ risultati della letteratura riguardarono principalmente valutazioni soggettive e solamente in due esperienze cliniche furono prese in considerazione misure oggettive con risultati discordanti. La xerostomia fu analizzata in pochi studi, con benefici differenti rispetto ai sintomi ostruttivi. La tempistica ideale per la videoendoscopia delle ghiandole salivari necessita di ulteriori analisi, al fine di definire la miglior gestione delle scialoadeniti ostruttive radioiodio-indotte.

PAROLE CHIAVE: Scialoadenite $\bullet$ Radioiodio $\bullet$ Scialoendoscopia $\bullet$ Ghiandole salivari $\bullet$ Endoscopia

Acta Otorhinolaryngol Ital 2017;37:155-159

\section{Introduction}

Salivary gland toxicity after radioiodine therapy is a widely documented adverse effect of radioactive iodine $\left({ }^{131} \mathrm{I}\right)$ in the treatment of differentiated thyroid cancers ${ }^{1}$. Swelling, pain and xerostomia, usually bilateral, are present in $2 \%$ to $67 \%$ of the ${ }^{131} \mathrm{I}$ exposed population ${ }^{2}$. Epidemiological data are still unclear because many factors can influence post-radioiodine salivary dysfunction: dose and timing of administered ${ }^{131} \mathrm{I}$, previous history of salivary gland disorders as well as other causes of xerostomia or increased ${ }^{131}$ I retention ${ }^{23}$. Salivary gland injuries can be quantified by technetium scintigraphy, but the total cumulative ${ }^{131}$ I dose may not strictly relate with clinical manifestations ${ }^{45}$. Clinical onset may occur early (within 48 hours) or late (3-6 months) after irradiation. Radiation damage to the salivary glands results from their selective ability 
of uptake and concentrate iodine as high as 7-700 times plasma levels, probably through a sodium/potassium/ chloride cotransporter ${ }^{6-9}$. Furthermore, ${ }^{131} \mathrm{I}$ induced harmful effects appear to be related to increased permeability of the gland vascular endothelium leading to leakage of plasma proteins and electrolytes. Adverse events include parenchymal injuries and salivary duct obstructions that trigger an inflammatory vicious circle able to amplify ${ }^{131}$ I uptake. More frequently involved, serous glands express a greater ability to concentrate iodine in comparison with mucous ones. Prevention and management of radioiodineinduced sialadenitis are widely debated in literature, and contradictory data are available concerning the adoption of sialagogues and anti-inflammatory drugs to avoid recurrences $^{2}$. Proper patient education, hydration with salivary gland massage and antibiotic administration in case of suppurative evolution represent the standard management of sialadenitis with estimated benefit in about $70 \%$ of cases ${ }^{1011}$. In 2006, for the first time, 15 patients suffering from sialadenitis secondary to ${ }^{131} \mathrm{I}$ underwent sialendoscopy with advantages in all cases following a single procedure only, under local anaesthesia ${ }^{12}$. The promising results of this inedited therapeutic option, led to new international experiences that have not been compared or analysed. The aim of the present study was to carry out a comprehensive review of salivary gland videoendoscopy applied to radioiodine-induced sialadenitis, in order to assess the impact of this procedure on outcomes.

\section{Materials and methods}

A systematic literature search was conducted using electronic databases (Medline, Embase, Scopus). The research strategy was performed combining intervention-specific terms ("sialoendoscopy", "sialendoscopy", "endoscopy") with disease-specific terms ("radioiodine-induced sialadenitis", "radioiodine sialoadenitis", "radioiodine", "131 I"). Levels of evidence were assigned according to the Oxford
Centre for Evidence based Medicine ${ }^{13}$. Inclusion criteria for published studies where the following: (1) randomised controlled trial, prospective and retrospective studies; (2) evaluation and description of sialendoscopic outcomes in patients suffering from typical ${ }^{131}$ I-induced sialadenitis, such as swelling, pain and xerostomia. Review articles, case reports, abstracts without a full text, letters and editorials were excluded, as well as non-English publications. The primary endpoint of this review was to evaluate the success rate of interventional sialendoscopy assessed as a reduction ("improved" patients) and/or resolution ("cured" patients) of salivary gland painful swellings. Secondary endpoints were: sialendoscopic findings, preand postoperative assessment of salivary gland function (by scintigraphy), pre- and postoperative evaluation of xerostomia, postoperative morbidity defined as all complications following sialendoscopy, percentage of gland excision after sialendoscopy. The last search was conducted on $30^{\text {th }}$ September 2016.

\section{Results}

Eight studies satisfied the inclusion criteria: levels of evidence ranged between 3 and 4 in all studies (Table I). All enrolled patients complained of two or more recurrent events of sialadenitis after radioiodine therapy. In seven studies, all patients were submitted to interventional sialendoscopy only after conservative medical treatment failures. The median time from radioiodine treatment to sialendoscopy was 11 months, ranging from $4.5^{11}$ to $16^{10}$ months (Table II). Interestingly, only in Wu et al. ${ }^{17}$, enrolled patients had never attempted conservative treatments before sialendoscopy. All authors, except Nahlieli et al. ${ }^{12}$, reported the mean dose of radioiodine, which ranged from $107 \mathrm{mCi}^{16}$ to 250 $\mathrm{mCi}{ }^{10}$, with a mean cumulative radioiodine dose of 163.7 $\mathrm{mCi}$. When reported, $74.7 \%$ received a single radioiodine treatment, and the remaining $25.3 \%$ underwent multiple treatments. The overall population was composed of 122

Table I. Clinical studies.

\begin{tabular}{|c|c|c|c|c|c|}
\hline Author, year & No. of patients & $\begin{array}{l}\text { No. of } \\
\text { sialendoscopies }\end{array}$ & Sialendoscope; size & Mean follow-up & $\begin{array}{l}\text { Level of } \\
\text { evidence }\end{array}$ \\
\hline Nahlieli, $2006^{12}$ & 15 & 15 & $\mathrm{NA} ; 1.3 \mathrm{~mm}$ & NA & 4 \\
\hline Kim, $2007^{11}$ & 6 & 6 & $N A ; N A$ & NA & 4 \\
\hline Bomeli, 200914 & 12 & 32 & $\begin{array}{l}\text { Marchal sialendoscope (Karl Storz, Tuttlingen, } \\
\text { Germany); } 1.3 \mathrm{~mm}\end{array}$ & NA & 4 \\
\hline Prendes, $2012^{10}$ & 11 & 29 & $\begin{array}{l}\text { Marchal sialendoscope (Karl Storz, Tuttlingen, } \\
\text { Germany); } 1.3 \mathrm{~mm}\end{array}$ & 14.4 months & 4 \\
\hline De Luca, $2014^{15}$ & 30 & 80 & $N A ; N A$ & NA & 4 \\
\hline Bhayani, $2015^{16}$ & 26 & 68 & Karl Storz sialendoscope (El Segundo, CA); NA & 23.4 months & 4 \\
\hline Wu, $2015^{17}$ & 12 & 19 & $\begin{array}{l}\text { PolyDiagnost sialendoscope (Hallbergmoos, Germany); } \\
\text { NA }\end{array}$ & NA & 4 \\
\hline Kim, $2016^{18}$ & 10 & 15 & Karl Storz sialendoscope (Tuttlingen, Germany); $1.1 \mathrm{~mm}$ & 5 months & 3 \\
\hline
\end{tabular}


Table II. Demographic and clinical data.

\begin{tabular}{|c|c|}
\hline \multicolumn{2}{|l|}{ Patients } \\
\hline Number of patients & 122 \\
\hline \multicolumn{2}{|l|}{ Sex } \\
\hline Male & $13.8 \%$ \\
\hline Female & $86.2 \%$ \\
\hline Mean age & 45.9 years \\
\hline \multicolumn{2}{|l|}{ Histology* } \\
\hline Papillary thyroid carcinoma & $79.8 \%$ \\
\hline Follicular thyroid carcinoma & $14.4 \%$ \\
\hline Other histologies & $5.8 \%$ \\
\hline \multicolumn{2}{|l|}{ Cumulative radioiodine dose (mCi) } \\
\hline Mean dose (min-max) & $163.7(107-250)$ \\
\hline \multicolumn{2}{|l|}{ Salivary glands submitted to sialendoscopy* } \\
\hline Parotid gland & $75.7 \%$ \\
\hline Submandibular gland & $24.3 \%$ \\
\hline \multicolumn{2}{|l|}{ Main sialendoscopic findings * } \\
\hline Stenosis & $46.3 \%$ \\
\hline Mucous plugs & $39.4 \%$ \\
\hline Sialodochitis & $14.3 \%$ \\
\hline \multicolumn{2}{|l|}{ Sialendoscopy } \\
\hline No. of primary treatments performed (\%) & $240(90.9 \%)$ \\
\hline No. of secondary treatments performed (\%) & $24(9.1 \%)$ \\
\hline \multicolumn{2}{|l|}{ Time from radioiodine to sialendoscopy } \\
\hline Median time (range), months & $11(4.5-16)$ months \\
\hline
\end{tabular}

patients (13.8\% males, $86.2 \%$ females), mean age 45.9 years, with greater involvement of parotid glands $(75.7 \%)$ submitted to sialendoscopy compared to submandibular glands $(24.3 \%)$. In $79.8 \%$ of patients, ${ }^{131} \mathrm{I}$ had been given for papillary thyroid carcinoma, in $14.4 \%$ for follicular thyroid carcinoma and in the remaining 5.8\% for other histologies. Overall, 240 sialendoscopies in 122 patients were carried out as primary treatment, consequently it may be assumed that multiple glands were often submitted simultaneously to interventional sialendoscopy in the same patient. The type of anaesthesia was specified in 4 studies: Nahlieli et al. ${ }^{12}$ and De Luca et al. ${ }^{15}$ performed all the procedures under local anaesthesia; Prendes et al. ${ }^{10}$ and Bhayani et al. ${ }^{16}$ opted for general anaesthesia. Only Prendes et al. ${ }^{10}$ reported one case of unsuccessful cannulation of the duct. When reported, stenosis was the most relevant endoscopic finding $(46.3 \%)$ followed by fibrinous debris/mucous plugs and sialodochitis in $39.4 \%$ and $14.3 \%$ of patients respectively. No studies reported the type of stenosis according to Koch classification ${ }^{19}$. All therapeutic procedures comprised irrigation with isotonic saline solution plus steroids (of different types according to each study), with the exception of the Wu et al. series ${ }^{17}$, in which sterile saline solution was mixed with gentamicin. In all cases, stenosis management required
Table III. Therapeutic success after interventional sialendoscopy.

\begin{tabular}{ll} 
Therapeutic Success* & \\
Complete therapeutic success (\%) & $40(33.1 \%)$ \\
After primary procedure (\%) & $40(100 \%)$ \\
After secondary procedures (\%) & 0 \\
Partial therapeutic success (\%) & $68(56.2 \%)$ \\
After primary procedure (\%) & $64(94.1 \%)$ \\
After secondary procedures (\%) & $4(5.9 \%)$ \\
Unsuccessful treatment (\%) & $13(10.7 \%)$ \\
TOTAL (\%) & $121(100 \%)$ \\
\hline${ }^{\star}$ Therapeutic success was referred to the number of patients \\
${ }^{*}$ Total number of patients was 121 because 1 patient was lost to follow-up
\end{tabular}

multiple techniques involving instrumental and hydraulic ductal dilation. Balloon dilation, as well as salivary stent positioning, were performed when needed, but no detailed data about the number of cases was available. No clinical study reported the frequency of sialadenitis before and after sialendoscopy, even though a high success rate $(89.3 \%)$ was documented in all clinical trials with a complete resolution of symptoms in $33.1 \%$ of the overall population and partial improvement in $56.2 \%$ (Table III). When successfully performed (108 patients), sialendoscopy was effective as primary treatment in 104 patients $(96.3 \%)$ and as a further therapeutic option in only 4 patients $(3.7 \%)$. In $10.7 \%$ of cases, salivary gland endoscopy did not provide an advantages for sialadenitis recurrence. One case of parotidectomy was carried out, with an overall percentage of gland excision of $0.8 \%{ }^{10}$. Only $\mathrm{Kim}^{18}$ et al. and $\mathrm{Wu}$ et al. ${ }^{17}$ analysed the functional outcome of sialendoscopy by salivary gland scintigraphy. In the first study ${ }^{18}$, pre- and post-sialendoscopy outcomes did not differ in uptake ratio, maximum accumulation and secretion by salivary gland scintigraphy. Differently, in Wu et al. ${ }^{17}$ the scintigraphy results showed a statistically significant higher uptake ratio and excretion fraction after interventional sialendoscopy. Concerning xerostomia, only Bhayani et al. ${ }^{16}$ and Kim et al. ${ }^{18}$ quantitatively assessed saliva production and evaluated dry mouth symptoms with a standard quality of life xerostomia questionnaire. Bhayani et al. ${ }^{16}$ observed a partial or complete relief of xerostomia symptoms in $77.3 \%$ of patients and sialometric data revealed a statistically significant difference in saliva production at 6 months following sialendoscopy for unstimulated salivary flow. In Kim et al. ${ }^{18}$, xerostomia-related symptom scores after sialendoscopy did not differ significantly in comparison with pre-endoscopic scores and there were no statistically significant differences between pre- and post-sialendoscopy stimulated salivary flow rate. No major adverse events were documented in any study. 


\section{Discussion}

In 1805, Philipp Bozzini announced in a daily German newspaper the development of a novel device that some years later was considered the progenitor of current endoscopes: the Lichtleiter or "Light Conductor" ${ }^{20}$. Since then, the evolution of endoscope-assisted techniques has revolutionised the concept of surgery introducing a new era of minimally-invasive medicine. This change of perspective was made possible by continuous progress in medical knowledge and technology with a positive influence in many fields of healthcare. From its first documentation in early $1990 \mathrm{~s}^{21} 22$, salivary gland videoendoscopy or sialendoscopy was largely applied in diagnosis and treatment of sialolithiasis and salivary duct stenosis with significant results ${ }^{23-25}$. The potential implications of this innovative tool were noted by the increasing number of published studies, as well as by the further applications in patients suffering from obstructive salivary gland disorders 2627 . Radioiodine-induced sialadenitis represents one of the latest employments of sialendoscopy: even if many authors have advocated its usefulness, debate is still open on the real effectiveness of this procedure and a comprehensive review had never been performed. According to our literature analysis, 122 patients underwent 240 sialendoscopic procedures as primary treatment, followed by 24 secondary sialendoscopies. The vast majority of patients were women (86.2\%) probably due to the epidemiological distribution of thyroid carcinomas susceptible to radioiodine therapy. The parotid gland was most frequently affected according with the higher concentration of serous acini as well as a lower clearance rate of salivary flow in comparison with submandibular gland ${ }^{28} 29$. Duct stenosis and mucous plugs were observed in $85.7 \%$ of endoscopic findings, supporting the role of ductal obstruction in the pathophysiology of radioiodine sialadenitis. In all, $89.3 \%$ of patients experienced a complete or partial resolution of sialadenitis recurrences and parotidectomy was advocated only in 1 case ${ }^{10}$. Mean follow-up period was specified in only three studies (Table I). In all studies, with the exception of Wu et al. ${ }^{17}$, interventional sialendoscopy was performed in case of medical treatment failure and after a median time of 11 months from ${ }^{131} \mathrm{I}$ therapy, both indicating the chronicity of the disease prior to sialendoscopy.

Despite the encouraging results, some critical considerations are necessary. The success rate was the result of different therapeutic strategies considering the type of steroid irrigation, the use of hydraulic, instrument and/or balloon dilation, the adoption of salivary stents, the ductal injection of antibiotics and the specific timing of sialendoscopic procedures. Moreover, the relief of painful swellings was mainly limited to subjective reports of symptomatic improvement, lacking a detailed description of the frequency of recurrence and a validated objective measurement. Only two studies quantitatively assessed salivary gland function by salivary scintigraphy, with contradictory results. According to Kim et al. ${ }^{18}$, there were no significant differences in functional outcomes between pre- and postoperative sialendoscopy, even if obstructive symptoms were always improved. Wu et al. reported improved salivary gland scintigraphy scores in $78.9 \%$ of glands in line with better symptomatic results ${ }^{17}$. Interestingly, the two studies mostly differed in the time to treatment (mean 13 months versus "early treatment" not further specified), in the mean cumulative ${ }^{131} \mathrm{I}$ dose (more than $150 \mathrm{mCi}$ versus $125 \mathrm{mCi}$ ), in the type of ductal stenosis regarding site, number and severity (not comparable due to the lack of data) and finally in study design (prospective versus retrospective). Subjective and objective assessment of xerostomia was limited to few patients in two clinical studies, with dissimilar results. Bhayani et al. ${ }^{16}$ documented symptomatic and sialometric benefits after sialendoscopy, differently from Kim et al. ${ }^{18}$ in which xerostomia and obstructive symptoms responded differently after sialendoscopy. The safety of sialendoscopy was supported by all studies with no major adverse events documented.

\section{Conclusions}

Recently, sialendoscopy has been advocated as an attractive diagnostic and therapeutic choice in patients with radioiodine-induced sialadenitis who are unresponsive to medical treatments. Eight international experiences have reported promising results with improvement of painful swellings in $89.3 \%$ of the cases and no major adverse events. However, small population sizes, the absence of randomised studies and heterogeneous follow-up times as well as different interventional sialendoscopic strategies strongly weaken the overall level of evidence. Furthermore, objective outcomes are limited to few studies with different methods of study and dissimilar results. Optimal timing of salivary gland videoendoscopy needs to be further analysed to define the best management strategy of radioiodine-induced obstructive sialadenitis.

\section{References}

1 Lee SL. Complications of radioactive iodine treatment of thyroid carcinoma. J Natl Compr Canc Netw 2010;8:127786.

2 Van Nostrand D. Sialoadenitis secondary to ${ }^{131}$ I therapy for well-differentiated thyroid cancer. Oral Dis 2011;17:154-61.

3 Mandel SJ, Mandel L. Radioactive iodine and the salivary glands. Thyroid 2003;13:265-71.

4 Hyer S, Kong A, Pratt B et al. Salivary gland toxicity after radioiodine therapy for thyroid cancer. Clin Oncol ( $\mathrm{R}$ Coll Radiol) 2007; 19:83-6.

5 Caglar M, Tuncel M, Alpar R. Scintigraphic evaluation of salivary gland dysfunction in patients with thyroid cancer after radioiodine treatment. Clin Nucl Med 2002;27:767-71.

6 Freinkel N, Ingbar SH. Concentration gradients for inorgan- 
ic $I 131$ and chloride in mixed human saliva. J Clin Invest 1953;32:1077-84.

7 Myant NB. Iodine metabolism of salivary glands. Ann N Y Acad Sci 1960;85:208-14.

8 Rice DH. Advances in diagnosis and management of salivary gland diseases. West J Med 1984;140:238-49.

9 Schiff L, Stevens CD, Molle WE, et al. Gastric (and salivary) excretion of radioiodine in man (preliminary report). $\mathrm{J}$ Natl Cancer Inst 1947;7:349-54.

10 Prendes BL, Orloff LA, Eisele DW. Therapeutic sialendoscopy for the management of radioiodine sialadenitis. Arch Otolaryngol Head Neck Surg 2012;138:15-9.

11 Kim JW, Han GS, Lee SH, et al. Sialoendoscopic treatment for radioiodine induced sialadenitis. Laryngoscope 2007;117:133-6.

12 Nahlieli O, Nazarian Y. Sialadenitis following radioiodine therapy - a new diagnostic and treatment modality. Oral Dis 2006;12:476-9.

13 Phillips B, Ball C. Levels of Evidence and Grades of Recommendation. Oxford: Oxford Centre for Evidence-Based Medicine; 2001.

14 Bomeli SR, Schaitkin B, Carrau RL, et al. Interventional sialendoscopy for treatment of radioiodine-induced sialadenitis. Laryngoscope 2009;119:864-7.

15 De Luca R, Vicidomini A, Trodella M et al. Sialoendoscopy: a viable treatment for $\mathrm{I}(131)$ induced sialoadenitis. Br J Oral Maxillofac Surg 2014;52:641-6.

16 Bhayani MK, Acharya V, Kongkiatkamon S, et al. Sialendoscopy for patients with radioiodine-induced sialadenitis and xerostomia. Thyroid 2015;25:834-8.

$17 \mathrm{Wu} \mathrm{CB}, \mathrm{Xi} \mathrm{H}$, Zhou Q, et al. Sialendoscopy-assisted treatment for radioiodine-induced sialadenitis. J Oral Maxillofac Surg 2015;73:475-81.

18 Kim YM, Choi JS, Hong SB, et al. Salivary gland function after sialendoscopy for treatment of chronic radioiodine-induced sialadenitis. Head Neck 2016;38:51-8.
19 Koch M, Iro H, Zenk J. Sialendoscopy-based diagnosis and classification of parotid duct stenoses. Laryngoscope 2009;119:1696-703.

20 Morgenstern L. The 200 $20^{\text {th }}$ anniversary of the first endoscope: Philipp Bozzini (1773-1809). Surg Innov 2005;12:105-6.

21 Katz P. New method of examination of the salivary glands: the fiberscope. Inf Dent 1990;72:785-6.

22 Königsberger R, Feyh J, Goetz A, et al. Endoscopic controlled laser lithotripsy in the treatment of sialolithiasis. Laryngorhinootologie 1990;69:322-3.

${ }^{23}$ Gallo A, Capaccio P, Benazzo M, et al. Outcomes of interventional sialendoscopy for obstructive salivary gland disorders: an Italian multicentre study. Acta Otorhinolaryngol Ital 2016;36:479-85.

${ }^{24}$ Capaccio P, Torretta S, Ottaviani F, et al. Modern management of obstructive salivary diseases. Acta Otorhinolaryngol Ital 2007;27:161-72.

25 Strychowsky JE, Sommer DD, Gupta MK, et al. Sialendoscopy for the management of obstructive salivary gland disease: a systematic review and meta-analysis. Arch Otolaryngol Head Neck Surg 2012;138:541-7;

26 Gallo A, Benazzo M, Capaccio P, et al. Sialoendoscopy: state of the art, challenges and further perspectives. Round Table, $101^{\text {st }}$ SIO National Congress, Catania 2014. Acta Otorhinolaryngol Ital 2015;35:217-33.

27 Canzi P, Occhini A, Pagella F, et al. Sialendoscopy in juvenile recurrent parotitis: a review of the literature. Acta Otorhinolaryngol Ital 2013;33:367-73.

28 Jeong SY, Kim HW, Lee SW, et al. Salivary gland function 5 years after radioactive iodine ablation in patients with differentiated thyroid cancer: direct comparison of pre- and postablation scintigraphies and their relation to xerostomia symptoms. Thyroid 2013;23:609-16.

29 La Perle KM, Kim DC, Hall NC, et al. Modulation of sodium/iodide symporter expression in the salivary gland. Thyroid 2013;23:1029-36.

Address for correspondence: Pietro Canzi, Department of Otorhinolaryngology, IRCCS Policlinico San Matteo Foundation and University of Pavia, viale Camillo Golgi 19, 27100, Pavia, Italy. Fax +390382 528184. E-mail: pietro.canzi@unipv.it 